\title{
GNSS availability monitoring method for railway transport
}

\author{
Vladislav Demyanov ${ }^{1, *}$, Boris Shurygin ${ }^{1}$, and Olga Imarova ${ }^{1}$ \\ ${ }^{1}$ Irkutsk State Transport University, 664074 Irkutsk, Russia
}

\begin{abstract}
The article studies relevant problem of real time monitoring the availability of the required GNSS navigation characteristics, which is required for railway rolling stock traffic automation. As prototypes, the main approaches to monitoring the availability of the required navigation characteristics of WAAS EGNOS wide area differential systems users were analyzed. It was shown that the use of the total probability of violation of the required navigation characteristics without decomposition of an equivalent range error is an appropriate approach for building the algorithm for monitoring the availability of navigation support for transport applications. The method of monitoring the availability of required navigation characteristics was proposed for automated railway traffic control tasks.
\end{abstract}

\section{Introduction}

Full-scale introduction of GLONASS in railway transport is guided by widespread introduction of the coordinate method of automatic traffic control. This method is based on the use of "virtual traffic lights", mobile block sites and virtual zones of obstacle approaching.

There is a number of problems that prevent introduction of intelligent transport systems based on satellite navigation on the Russian Railways. These problems include the following: actual unpredictability of the current positioning accuracy; restrictions on the use of accurate geospatial data; insufficient availability of digital maps of railway facilities within territorial entities of the Russian Federation [1, 2]. Works of B. A. Lyovin, I. N. Rosenberg, S. I. Matveev, E. N. Rosenberg, A. S. Matveev are devoted to introduction of satellite navigation on domestic railways. [3-5].

The necessary prerequisite for ensuring the required navigation characteristics (RNC) in transport is the use of GLONASS functional add-ons, i.e., local and wide-area differential systems. Differential navigation means provide both high positioning accuracy and effective RNC availability real time monitoring [6]. Thus, full-scale introduction of differential navigation on railways opens wide prospects for using all potential benefits from introduction of GLONASS as the main element of intelligent transport systems.

Wide-area differential systems (WADS) have been sufficiently commissioned abroad long ago, e.g., WAAS (USA) and EGNOS (European Union). In most cases, these systems

\footnotetext{
*Corresponding author: sword1971@yandex.ru
} 
ensure positioning accuracy with the residual error of 1-3 m with the RNC availability of not worse than 0.9999 with the user warning time of not more than $10 \mathrm{~s}$ [7]. Despite these high characteristics, insufficient reliability in the following conditions of irregular impacts remains the bottleneck of the WADS: geomagnetic disturbances of the ionosphere, electromagnetic interference, screening of signals of part of visible satellites by infrastructure facilities, etc. Unfortunately, the same can be stated about the domestic WADS GLONASS, known under abbreviation RSDKM [8].

The best solution for transport applications would be using local departmental differential systems. These are already widely used in radio engineering systems for aircraft guidance and landing [9]. But even here the issue of RNC monitoring with regard to irregular impacts has not been adequately elaborated. And so far the issue of full-scale use of differential navigation in railway transport for implementation of intelligent transport systems (ITS) has not been considered in practice yet.

In this paper, the issue of real time monitoring of RNC availability of GNSS users for transport applications is considered. Comparison of main advantages and disadvantages of the two main concepts of availability monitoring of the RNC used in WASS and EGNOS WADS is performed. The method of monitoring the availability of required navigation characteristics is proposed for automated railway traffic control tasks.

\section{Concepts of RNC integrity monitoring used in WAAS and EGNOS systems}

The RNC integrity monitoring algorithms of WAAS [10] (SBAS+GPS) and EGNOS (SBAS+Galileo) [11] were designed for use in aircraft navigation and landing systems [12]. Unfortunately, the similarly detailed technological information on the existing availability monitoring algorithms for RNC of RSDKM users (SBAS + GLONASS), is not generally available, therefore, it is not considered herein.

The general part of the algorithm for assessing the current availability of the RNC in the aforementioned foreign WADSs is as follows. The main station calculates the integrity parameters of the system segments and differential corrections within certain limits of the confidence intervals for components of range-errors of satellites in the zone of visibility. Based on this, current RNC integrity is evaluated in the system user's equipment. The integrity data is provided in the form of calculated current protection levels (PLs) in the horizontal and vertical plane in the local coordinate system. The user's receiver compares the calculated protection levels with the confidence intervals set for the horizontal plane (HAL) and the vertical plane (VAL) for the selected flight phase. If one of the protection levels goes beyond the confidence interval, the sign of the system integrity violation is generated.

However, the final technological algorithms for assessing the current RNC integrity in these systems differ. The WAAS technological algorithm assumes the following: 1) serviceability of visible navigation satellites, if the satellite itself does not produce the sign of "health" violation; 2) decomposition of the full range-error into separate components of the equivalent range-error: ionospheric error, tropospheric error, multipath error, and ephemeris error. With that, locally-dependent range-errors (ionospheric, tropospheric and multipath errors) are further converted into an averaged functionally-dependent form suitable for use anywhere in the wide work area [13].

The technological algorithm of integrity control in the EGNOS system works differently. It assumes independent monitoring of "health" of each of the visible satellites. Besides, this algorithm uses the full probability of the RNC violation without decomposition of the full range-error by main sources [14]. 
The RNC availability assessment used in WAAS in terms of plane and height is as follows:

$$
\begin{gathered}
H P L=K_{H} \cdot d_{\text {major }} \\
V P L=K_{V, P A} \cdot d_{v}
\end{gathered}
$$

where:

$K_{H}, K_{V}$ is the coefficient that indicates the margins of the confidence interval of the positioning error in terms of plane and height with the confidence probability of $\mathrm{P}=1-10^{-7}$;

$d_{\text {major }}$ is the length of projection of the main ellipse projection semi-axis of dissipation of the error in positioning of the system user onto the plane in the local coordinate system, equal to the following:

$$
\begin{gathered}
d_{\text {major }}=\sqrt{\frac{d_{\text {east }}^{2}+d_{\text {north }}^{2}}{2}+\sqrt{\left(\frac{d_{\text {east }}^{2}+d_{\text {norh }}^{2}}{2}\right)^{2}+d_{E N}^{2}}} \\
d_{E N}=\sqrt{d_{\text {east }}^{2}+d_{\text {north }}^{2}}
\end{gathered}
$$

$d_{\text {east }} d_{\text {north }}, d_{V}$ are the semi-axes of the dissipation ellipse of the positioning error in the direction to the east, north and in height in the local coordinate system, respectively.

The RNC integrity monitoring algorithm, which is used as part of software and algorithmic support in the EGNOS system, directly estimates the expected probability of dangerous misalignment of the $\mathrm{P}_{\mathrm{HMI}}$ (probability of hazardous misleading information) about the actual and expected positioning error. With that, the system performs calculation of the current value of the $\mathrm{P}_{\mathrm{HMI}}$ probability and its comparison to the set permissible level. If the $\mathrm{P}_{\mathrm{HMI}}$ exceeds the permissible set limit, this means that the estimated object state vector is outside the established RNC margins with the specified probability. The user must be immediately notified of this.

The mathematical notation of the algorithm for estimating the RNC availability in terms of plane and height in the EGNOS system is as follows:

$$
\begin{aligned}
& P_{H M I}(V A L, H A L)=1-\operatorname{erf}\left(\frac{V A L}{\sqrt{2} \cdot \sigma_{u, V, F F}}\right)+e^{\frac{H A L^{2}}{2 \xi_{F F}^{2}}}+\frac{1}{2} \sum_{j=1}^{N} P_{\text {fail }_{,} \text {sat }} \cdot((1- \\
& \left.\left.\operatorname{erf}\left(\frac{V A L+\mu_{u, V}}{\sqrt{2} \cdot \sigma_{u, V, F M}}\right)\right)+\left(1-\operatorname{erf}\left(\frac{V A L-\mu_{u, V}}{\sqrt{2} \cdot \sigma_{u, V, F M}}\right)\right)\right)+\sum_{j=1}^{N}\left(P_{\text {fail }, s a t_{j}} \cdot(1-\right. \\
& \left.\left.\chi_{2, \delta_{u, H}}^{2} \operatorname{cdf}\left(\frac{H A L^{2}}{\xi_{F M}^{2}}\right)\right)\right)
\end{aligned}
$$

Where:

$\mu_{u, V}$ is the permissible initial deviation of the positioning error in the vertical plane;

$\xi$ is equivalent to $d_{\text {major }}$ specified in (3);

$\sigma_{u, V_{s} F M}$ are unaccounted range-errors;

$\mathrm{P}_{\text {fail,sat }}$ is the probability of technical failure in the satellite operation. 
The obvious disadvantage of the SBAS + GPS concept is that it is based on the health of all visible GPS satellites. In the case of unaccounted anomalies in the satellite operation, this can cause unpredictable deterioration in operation of the entire system.

The disadvantage of the SBAS+Galileo concept is that the main function for estimating the expected range-errors is shifted to the user equipment. On the one hand, it increases the availability and reliability of the RNC integrity monitoring, but, on the other hand, it puts the final result of the system operation in dependence on functioning peculiarities of the user navigation equipment of various manufacturers. That is, the possibility of strict unification, regulation and certification of the RNC integrity monitoring process, is violated, particularly for departmental users.

With consideration of the main ideas, as well as the disadvantages of the aforementioned RNC integrity monitoring algorithms, let us turn to consideration of the new algorithm. The algorithm proposed below is designed to monitor the RNC availability with positioning of the object on the plane with a rigidly defined motion path.

\section{The RNC availability monitoring algorithm for the use in railway transport}

The proposed method is based on the use of measurements of the full range-error of visible navigation satellites on the reference monitoring and correcting station of the local differential system (LDS). With that, no decomposition of range-errors is performed, and the RNC availability is monitored in the horizontal plane with consideration of motion along the rigidly defined path.

The availability of positioning must be determined from the standpoint of the full probability of the RNC availability in the LDS coverage area in the following form:

$$
W=P(A) \times P(B) \cdot P(C \mid A, B) \cdot\left(1-P_{F A U L T}\right) \times W_{P D O P}
$$

where $\mathrm{A}$ is the event at which GLONASS and LDS equipment is in the serviceable state;

$\mathrm{B}$ is the event at which GLONASS equipment is serviceable;

$\mathrm{C}$ is the event at which positioning accuracy corresponds to the RNC at the stage of solving a specific transport problem;

$\left(1-P_{F A U L T}\right)$ is the probability of positioning failure at the stage of solving a specific transport task;

$W_{P D O P}$ is the index that warns about the dangerous level of the expected positioning error, as a result of a sudden deterioration of geometric factor (PDOP).

Then, we believe that $P(A)=P(B)=1$. This corresponds to the case if independent monitoring of the GLONASS+LDS system technical state is not provided.

The probability of positioning failure at the stage of solving the problem can be estimated as the probability of occurrence of k-events (failures) at random instants within the transport problem solution interval $(\Delta \mathrm{T})$ using the Poisson law as follows [15]:

$$
P_{\text {FAULT }}=\frac{a^{k}}{k !} \cdot \exp (-a)
$$

where $\mathrm{k}=0,1,2, \ldots \mathrm{n}$ is the possible number of positioning failures within the monitoring period, $\Delta \mathrm{T}, a$ is the Poisson distribution parameter.

The peculiarities of the proposed general methodology for use on the railway are as follows: 
1) the train moves along a rigidly defined trajectory, therefore it is required to estimate not the unexpected positioning error in terms of plane, but the expected error in determining the current path ordinate (the braking distance length);

2) there is no need for warning the user of rapid deterioration of the positioning accuracy in the vertical plane, therefore, it is enough to estimate only the horizontal geometric factor for estimating of alarm index $W_{P D O P}$.

Thus, estimation of the RNC availability of in terms of the available positioning accuracy for navigational support of the railway transport takes the following form:

$$
P(C \mid A, B)=\exp \left(-0.5 \cdot\left[\frac{\left(X_{B R}-m_{X}\right)^{2}}{\sigma_{X}^{2}}+\frac{\left(Y_{B R}-m_{Y}-c \cdot \frac{\sigma_{Y}}{\sigma_{X}} \cdot\left(X_{B R}-m_{X}\right)\right)^{2}}{\sigma_{Y}^{2} \cdot\left(1-c^{2}\right)}\right]\right)
$$

where $\mathrm{c}$ is the coefficient of correlation between time ranges of positioning errors $\Delta X$ and $\Delta Y ; m_{X}=x_{t l}^{*}, m_{Y}=y_{t l}^{*}, \sigma_{X}, \sigma_{Y}$ is the mathematical expectation and the RSD of errors in positioning of the tail of the train in front (the "virtual red traffic light" location point). See the explanation of other components of expression (8) in Figure 1.

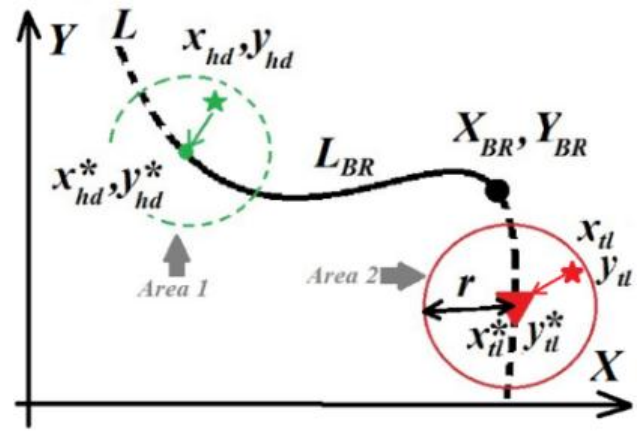

Fig.1. Elements of the train crash warning system.

The practical application of the method described by expression (8) is as follows. Firstly, one must learn the exact position of the path of movement along the railway (L) in the special railway coordinate system (X, Y). After learning coordinates L, one can calculate current braking distance $\left.L_{B R}\right)$ between point $x_{h d}^{*}, y_{h d}^{*}$ and $\left(X_{B R}, Y_{B R}\right)$ on the basis of the "speed-braking distance" normative curves known for this path section considering the train speed and mass. Coordinates of the forward train head $\left(x_{h d}, y_{h d}\right)$ and tail $\left(x_{t l}, y_{t l}\right)$ are estimated with the use of the GLONASS+LDS equipment. These coordinates are in the supposed center of the ellipses for dissipation of positioning errors (Area 1 and Area 2 in the figure). To calculate the length of the braking distance $\left(L_{B R}\right)$, let us recalculate the current coordinates of the train head $\left(x_{h d}, y_{h d}\right)$ for the nearest point on the railway path $\left(x_{h d}^{*}, y_{h d}^{*}\right)$. After determination of length $L_{B R}$ and the railway path coordinate, let us find the final point of the braking distance $\left(X_{B R}, Y_{B R}\right)$ on the railway path. If it has been found out in the course of calculation by formula (8) that the coordinates of the final braking distance point $\left(X_{B R}, Y_{B R}\right)$ fall within critical Region 2 , it is necessary to issue a warning about the RNC violation, since the current state of the system does not allow adequate estimating of the size of the approach zone with a temporary obstacle. Area 2 radius depends on the confidence admissible collision probability, which is established a priori. For example, with the confidence probability of 
"3 sigma" $(1-0.997=0.003)$, the radius of Area 2 is $r \approx 3 \cdot \sigma_{r}$, where $\sigma_{r}$ is the equivalent standard deviation of positioning errors in terms of plane, which is defined as: $\sigma_{r}^{2}=\max \left\{\sigma_{\Delta X}^{2}, \sigma_{\Delta Y}^{2}\right\}$.

The remaining elements in original equation (6) are defined as follows. The distribution parameter in (7) depends on the duration of interval $\Delta \mathrm{T}$ and distribution of the positioning errors time, which, in general, can be non-fixed during the $\Delta \mathrm{T}$ period. Therefore, determination of the Poisson law parameter supposes accumulation of experimental histograms for the system put into operation, and then smoothing out the histogram data with the help of the theoretical Poisson law by the least squares method:

$$
\sum_{k=0}^{n}\left(P_{k}-\frac{a^{k}}{k !} \times e^{-a}\right)^{2} \rightarrow \min
$$

where $\mathrm{n}$ is the maximum number of positioning errors in the series of observations.

Current alarm index $W_{P D O P}$ for the railway must be adopted to estimate the expected dangerous error only in terms of plane in the following form:

$$
\begin{gathered}
W_{P D O P}=\left\{\begin{array}{ll}
1, & \left(H D O P \leq \Pi_{H D O P}\right) \\
0, & \left(H D O P \geq \Pi_{H D O P}\right)
\end{array}\right\} \\
\Pi_{H D O P} \leq \frac{\left(\sqrt{\sigma_{X}^{2}+\sigma_{Y}^{2}}\right)_{\max }}{\sigma_{A R}}
\end{gathered}
$$

where the "max" index denotes the corresponding maximum allowable RSD of positioning errors on the plane in accordance with the RNC; $\sigma_{\Delta \mathrm{R}}$ is the RSD of rangeerrors, which is calculated by direct measurements on the signals of visible satellites on the CCS of the LDS during the observation period, $\Delta \mathrm{T}$.

In general, as one can see, the proposed RNC availability monitoring method can be used for automated railway traffic control tasks. The method algorithm takes into consideration all possible irregular effects on the integrated GLONASS+LDS system, and also provides for the possibility of considering the technical state of segments of the system itself.

\section{Conclusion}

The method proposed is based on estimation of the current statistics of positioning errors and the full range-error (without its decomposition) on a time scale close to real time and within the LDS work zone. This approach makes it possible to count on high reliability of the RNC availability control algorithm, even taking into consideration the impacts of unpredictable and irregular factors. Such impacts can be geomagnetic disturbances, powerful electromagnetic interference and screening of signals from some satellites by infrastructure facilities. In method proposed ensures the possibility of estimating the expected sharp deterioration in the positioning accuracy due to screening of signals of some visible satellites. With that, the current range-error statistics is taken into consideration. This property of the method proposed allows adapting the operation of the GLONASS+LDS system as part of the complex of intelligent transport systems, taking into consideration the expected impact of known railway infrastructure facilities. The issues of estimating the LDS work zone dimensions, the range-errors stationarity interval and the behavior of the positioning error dissipation ellipse semi-axes on the plane are still open. 


\section{References}

1. V.N. Tyapkin, E.N. Garin, Metody opredelenija navigacionnyh parametrov podvizhnyh sredstv s ispol'zovaniem sputnikovoj radionavigacionnoj sistemy GLONASS [Methods for determining navigational parameters of mobile assets using the GLONASS satellite radio navigation system] (SFU, Krasnoyarsk, 2012). (in Russian)

2. E.L. Afraymovich, Kosmicheskaja pogoda i kosmicheskij klimat [Space weather and space climate], Vol. 3, 427 (2013). (in Russian)

3. E.N. Rozenberg, A.S. Korovin, V.V. Batraev, O razvitii bortovyh i napol'nyh sistem kontrolja bezopasnosti, minimizirujushhih vlijanie chelovecheskogo faktora [Development of airborne and floor safety control systems, minimizing the impact of human factors] (Russian Railways JSC, Moscow, 2013). (in Russian)

4. S.I. Matveev, I.N. Rozenberg, Grafy i navigacija [Graphs and navigation] (Moscow, 2015). (in Russian)

5. I.D. Dolgiy, I.N. Rozenberg, S.V. Sokolov, V.I. Umanskiy, V.V. Kamenskiy, RU Patent 2468950 (16.05.2011). (in Russian)

6. A.I. Perov, V.N. Kharisova, GLONASS: principy postroenija i funkcionirovanija [GLONASS: principles of construction and operation] (Radiotehnika, Moscow, 2010). (in Russian)

7. Wide-Area Augmentation System Performance Analysis Report, 17 (William J. Hughes Technical Center, 2006), available at http://www.nstb.tc.faa.gov/REPORTS/waaspan17.pdf

8. V.V. Demyanov, Yu.V. Yasyukevich, Solnechno-zemnaja fizika [Solar-terrestrial physics] (ISU Pabl., Irkutsk, 2014). (in Russian)

9. Doc 9849 AN/457. Global Navigation Satellite System (GNSS) Manual (International Civil Aviation Organization, 2013). (in Russian)

10. Federal Aviation Administration, Satellite Navigation - WAAS - how it works (June 15, 2015), available at:

https://www.faa.gov/about/office_org/headquarters_offices/ato/service_units/techops/n avservices/gnss/waas/howitworks/.

11. European Global Navigation Satellite System Agency, About EGNOS, available at: https://egnos-user-support.essp-sas.eu/new_egnos_ops/egnos-system/about-egnos (May 09, 2018).

12. F. Kneissl, C. Stöber, Inside GNSS (January/February 2010).

13. V.V. Kurshin Doctoral thesis, Moscow Aviation Institute, Moscow, 2003. (in Russian)

14. EGNOS Safety of Life Service (SoL) SDD, Issue 3.1 (European GNSS Agency, 2016).

15. E.S. Venttsel, Teorija verojatnostej [Theory of probability] (Nauka, Moscow, 1969). (in Russian) 